\title{
MARITAL CONFLICTS RESOLUTION STYLES
}

\author{
Hatixhe Islami ${ }^{1}$
}

\begin{abstract}
Conflict as a social phenomenon has an important role in our lives, which is why it is so important to understand this phenomenon. That involves recognizing the mechanisms of emergence, development, methods of study and their resolution. The practice of social work and previous treatments with spouses shows that the marital relationship as an interpersonal relationship represents the specific basis for the emergence of conflicts. The obtained results are part of a study on the characteristics of marital relations and their influence on the choice of the spouses' patterns of behavior during conflict situations. The results suggest that the choice of different strategies of behavior in a situation of conflict among our respondents mainly depends on: the degree of insistence in fulfillment of personal interests, and the level of cooperation in addressing the interests of others. As a dominant style in marital conflict resolution our respondents use the avoiding style. During the study, gender differences between spouses, how they perceive, understand, and resolve marriage conflicts were found. Women are more critical toward their abilities to resolve conflict. In such situations they often use negative behavior, compared to men who are more likely to deny or avoid situations of conflict. Marriages where violence in involved are mainly based in destructive patterns of behavior in marital conflict resolution.
\end{abstract}

UDC Classification: 316.6, DOI: http://dx.doi.org/10.12955/cbup.v4.815

Keywords: marital conflicts, conflict resolution, gender, violence.

\section{Introduction}

This study aims at showing how much martial conflicts effect spouses in everyday life and what patterns of behavior and styles used to resolve them. Now-a-days we are faced with the fact that many marriages are conflicting due to the collapse of basic human values, which lead to changes in marital and family status, whether it is for structures, understanding, its meaning or function. The problem of marital conflict is one of the main topics during research in the field of marital relations. It is known that conflicts are an integral part of any sustainable marital relationship (Canary, Cupach, \& Serpe, 2001), and the knowledge in using the right styles to resolve them has a major impact on the stability, satisfaction and quality of marital relationships (Notarius, Lashley, \& Sullivan, 1997). Commitment and maintenance of marital relations is inciting spouses to find appropriate ways to manage mutual conflicts. How spouses as participants in a conflict situation perceive conflict is of great importance because any new marital conflict bears the consequences of the conflict that occurred long before that. The factors mentioned have a major impact on spouses whether they would hold a negative or a constructive approach on conflicts in general.

Many husbands are not able to analyze conflicts and exploit them in an appropriate way in order to potentially solve them because they do not have proper knowledge of styles, methods and preventive techniques for the resolution, management and transformation of marital conflicts. Obviously, the lack of such knowledge and skills in this field causes the the conflict to escalade by using violence.

The possession of certain skills causes spouses to feel strong and constructive in resolving conflicts. On the other hand, a large number of spouses oppress or hide their feelings in order to have a quiet marriage. When husbands oppress conflicts they unconsciously and uncontrollably prevent marital relations which lead to the appearance of psychosomatic disorders and diseases. Often unresolved marital conflicts are transformed into anger and resentment, which leads to insulation and building of barriers between spouses.

Conflict resolution styles for family and couples constitute some of the most intimate factions of human relationships. Conflict in itself is not destructive or negative if the spouses are familiar with the reasons leading to its appearance. Conflicts that lead to a better understanding of the problem, or encourage innovative and successive solutions are defined as constructive conflicts. In subjective terms they cause a feeling of satisfaction, confidence and curiosity, and stimulate creative thinking. Results of numerous studies confirm that the biggest indicator of long-term success in any relationship

\footnotetext{
${ }^{1}$ Hatixhe Islami, South East European University, Tetovo, Macedonia, h.islami@seeu.edu.mk
} 
is how spouses cope with their conflicts and the way they support each other and express their love in the quiet time with no problems or conflicts (Gottman, 1994).

\section{Literature Review}

Intensive interpersonal conflict research begins with social grievances that include the world in the 1960s, although the study of conflict dates back to 1980.

Psychologically speaking, conflicts result from the processing of information that affects our behavior and is closely linked to our emotional experience. Psychological approach to the study of conflict is characterized by its large influence on the quality of the personality psychological component. According to the classical psychoanalysis, conflicts cannot be avoided and the devastating impact on the personality of the individual cannot be prevented. Efforts should be targeted towards mitigating and minimizing the consequences by educational influences in the process of socialization. Conflict as a process begins when one party believes the other has damaged or attempted to hurt something they own or want. Power and resources occupy a central concept in explaining the behavior of individuals in the family. Despite the commitment and time of occurrence, all theorists believe that individuals during conflicting situations behave in accordance with their interests.

Theories that treat conflict as a negative occurrence think that conflicts are regarded as a threat. For the parties in the conflict its effects are negative and lead to destructive confrontation. On the contrary the theories that explain the conflict as a positive phenomenon, where conflict is considered useful as it encourages the conflicting parties to make efforts to solve the problem and reduce the tension and stress.

Marital nature is characterized as an intimate relation where the dominant feature is the continuous interaction between spouses, which is a strong and mutual interdependence of strong feelings between spouses. Conflicts are part of married life just like any other close ties (Straus, 2005; Wilmot \& Hocker 2007). The emergence of conflicts in marital life is normal because they lead to the strengthening of marital life which makes the marriage more durable than before. Though conflicts are common in marriage, the causes are different. The essence of conflict presentation can effect daily problems from the fulfillment of the responsibilities of marriage and family, to the presence of serious conflicts that may affect marriage and family (Čudina-Obradovič \& Obradovič, 2005).

Psychological research shows that $80-85 \%$ of families have conflicts, but depending on the presence and intensity, spouses use different strategies to solve them. The research shows that partners who are satisfied with their conjugal life mostly use structural styles of conflict resolution like a compromise style, and discuss their problems in a more open way. Styles that husbands use to resolve conflicts largely reflect the nature of their relationship which are also important indicators of satisfaction in the relationship and the duration of the relationship (Murray \& Holmes, 1995).

\section{Methodology}

The specificity of the problem required us to apply methods and techniques for collecting, processing and interpreting the data. Theoretical and practical analysis of obtained data will contribute to the discovery of relations established in the hypothetical system. Namely, which patterns of behavior and styles spouses use to resolve conflicts, whether there are differences in the use of certain styles of conflict resolution, if they are dependent on gender, and the presence of violence in marriage. Materials collected will be analyzed and interpreted. The research has used the test for diagnosing conduct in conflict situations (Thomas \& Kilmann, 1974) that aims to diagnose how much spouses tend to conduct conflicting attitude, which is characterized by constructive or destructive behavior during conflict resolution. To describe the type of people's behavior in a situation of conflict, the author applies the model of two-dimensional arrangement of conflicts, whereas primary dimensions consider the cooperation as positive attitude and competitiveness as negative behavior. In accordance with the type of behavior in conflict situations, conflict solving styles (rivalry, cooperation, compromise, avoidance and adaptation) are also defined.

\section{Results and discussions}

The results in this study suggest that the choice of different strategies of behavior in conflict situations among our respondents mainly depends on the degree of persistence to achieve personal interests and degree of cooperation in addressing the interests of others. The dominant style of conflict resolution 
from our respondents was crowd out style, a style characterized by a lack of responsibility for cooperation on the part of their husbands and low persistence in the pursuit of personal interests and needs. With this type of behavior spouses deny the existence and function of marital conflict, and display the dynamics of conflict. This behavioral style affects spouses to limit personal ability to deal with conflict situations. Although they perceive the existence of conflict, they remain passive to initiate the process of taking measures for its solution.

The choice of 'avoidance' as a style for marital conflict resolution indicates reduced confidence and a lack of developed social skills leading to the creation of internal conflicts between spouses.

Statistical differences in the use of certain styles of conflict resolution by the respondents

From comparative analyses, the results show that there are statistical differences in the use of styles for conflict resolution between: rivalry and cooperation $(t=-3803$ and $p<0: 01)$, rivalry and compromise $(\mathrm{t}=-4,201$ and $\mathrm{p}<0: 01)$, and rivalry and avoiding styles $(\mathrm{t}=-6.028$ and $\mathrm{p}<0: 01)$. The results show that among these styles there is a negative correlation which indicates that during growing conflict, spouses have a need to compete in order to satisfy their own interests, which reduces the level of cooperation and compromise and the expectation of avoiding the conflict. The results show that the spouses during the process of solving conflict constantly worry about personal goals and want to realize them by any means. From our respondents, choosing rivalry as a style is a model of destructive behavior for marital conflict resolution, accompanied by reduced marital interaction and impaired communication.

Major differences in the use of certain styles of marital conflict resolution depending on the gender of the spouses

The results show that the differences in the arithmetical environments are statistically important in terms of style rivalry $(t=3.082 ; \mathrm{p}<0.05)$ and style adaptation $(\mathrm{t} \sim 2,045 ; \mathrm{p}<0.05)$. The obtained results show that there are gender-based differences between spouses on how they perceive, understand, and resolve their conflicts. Female respondents, regardless of their husbands, use rivalry as a marital conflict resolution style. Women identify with the relationship and better perceive the problems because they are more involved with family obligations and expect more from the marital relationship. During conflict situations when women are underestimated, unfairly mocked or criticized by their husbands, they get competitive, which in some cases can result in distrust and suspicion, which affects the mood of the spouses. Feelings of personal injury influence women to include mechanisms for protection and response, using rivalry as a conflict resolution style. Conflicts between them are often associated with strong emotions because the assessment of personal interests and comparison with the interests of the spouse is often done unconsciously. Compared to women, men use avoidance and adaptation as marital conflict resolution style. In many cases men prefer to avoid the conflict, especially when the intensity of negative emotions is high. They try to think rationally, act calm and tend to make rational efforts to resolve the conflict in order to eliminate it before it becomes a sensitive issue for the other side. Gender differences in conflict resolution are due to socialising differences between females and males, as well as gender-specific differences in terms of social roles and expectations. Gender differences in the behavior of spouses during conflict situations also depend on the individual differences between spouses, cognitive processes as well as previous experience of the couple in conflict resolution.

Our results and the results of other researchers today reject the conclusions of the traditional theories according to which women in conflict resolution usually use passive strategy, unlike men who are active, successful and more effective in dealing with problems (Stone \& Neale, 1984).

Recent studies show that women are less satisfied with the marital life than men, because men have lower expectations form marital life compared to their wives as satisfaction is an important component in the quality of marriage.

On comparing marriages where violence is present and marriages where violence is absent, spouses use different styles of conflict resolution. A summary of the results, can conclude that the amount of value for $t$ and $p$ in terms of style rivalry, compromise and cooperation avoidance adaptation do not reach critically significant statistical value. The only differences occur in terms of rivalry style that 
partners use in marriages where there is violence. Differences in arithmetic environments are statistically significant, in terms of rivalry style $(t=3842$ and $\mathrm{p}<0: 01)$.

The results suggest that in marriages where there is violence, marital relations are mainly based in the destructive exchange of the need of both spouses for love, affection, understanding, comfort, opinion and respect. The dominance of rivalry as a style of marital conflict resolution in marriages where there is spousal violence, stems from the accumulated tension, which is a result of ignorance or lack of skill in constructive conflict resolution. The presence of negative interaction between the couple leads to frustration, anxiety, difficulty and loss of confidence which escalades the conflict and the use of physical violence.

\section{Conclusion}

Studies show that spouses, who have qualitative marital relationship, where there is love, mutual respect and equal share of obligations and marital responsibilities, prefer to use constructive styles to resolve the marital conflict. Spouses who have high aspirations to dominate over conflicting situations have low desire for the realization of common goals and interests. Spouses who try to avoid major conflicts are likely to dominate the conflict situation. In order to overcome marital conflicts in a constructive way, it is required that couples recognize the styles of conflict resolution or management of their marriage that will help them in acquiring social skills for constructive resolution of marital conflicts. Gaining social skills will allow spouses to gradually and tactically reconcile conflicting interests and differences, and try to balance strengths and needs.

Research done so far is an indicator of direct change or progress in this field to provide more qualitative marital relationship, because professional experience in our country in this field shows that in conflictual situations, spouses often react aggressively or withdraw, a way of behavior which prevents conflict resolution and leads to frustration, anxiety, concern, distrust, irritability and psychosomatic disorders.

Through perception of spousal dynamics in contributing to the opening of marriage and family counseling that will help spouses learn and develop their skills for constructive marital conflict resolution.

\section{References}

Canary, D. J., Cupach, W. R., \& Serpe, R. T. (2001). A Competence-based approach to examining interpersonal conflict Test of a longitudinal model. Communication.

Čudina-Obradović, M., \& Obradović, J. (2005). Psychology of marriage and family. Zagreb: Golden marketing - technical books.)

Gottman, J. M. (1994). What Predicts Divorce? The Relationship between Marital Processes and Marital Outcomes. Hillsdale, NJ: Lawrence Erlbaum.

Murray, S. L., \& Holmes, J. G. (1995). When is a fault not a frailty? The structure of resilient representations in dating relationships. Unpublished data, University of Waterloo.

Notarius, C. I., Lashley, S. L., \& Sullivan, D. J. (1997). Angry at your partner? Think again. U: Sternberg, R. J. \& Hojjat, M. (ur.); Satisfaction in Close Relationships. New York: The Guilford Press, 219-249.

Stone, A. A., \& Neale, J. M. (1984). New measures of daily coping: Development and preliminary results. Journal of Personality and Social Psychology, 46, 892-906.

Straus, M. A. (2005). Measuring intrafamily conflict and violence: The Conflict Tactics (CT) Scales. U: R. K. Bergen, J. L. Edleson i C. M. Renzetti (ur.). Violence against women: Classic papers (str. 187-197). Boston: Pearson Education Inc.:

Thomas, K. W., \& Kilmann, R. H. (1974). Thomas-Kilmann conflict MODE instrument.Tuxedo, New York: XICOM.

Wilmot, W. W., \& Hocker, J. L. (2007). Interpersonal Conflict. New York: McGraw-Hill. 